\title{
NONLINEAR OBSERVABILITY OF ACTIVATED SLUDGE PROCESS MODELS
}

\author{
F. Benazzi and R. Katebi \\ Industrial Control Center, \\ Department of Electronic and Electrical Engineering, \\ University of Strathclyde, 50 George street, Glasgow G1 1QE, UK. \\ E-mail: fbenazzi@eee.strath.ac.uk,r.katebi@eee.strath.ac.uk
}

\begin{abstract}
The main contribution of this paper is to present a non-linear observability analysis method of Activated Sludge Models (ASM), which are used in many control applications. The objective is to reduce the unobservable ASM1 model to an observable one that can be used to implement advanced estimation algorithms. Local observability is achieved under certain operating conditions but failed at some points in the whole domain of definition. Furthermore, piece-wise observability rank test is also performed with three measurements and compared with non-linear observability. Simulation results are presented to demonstrate the proposed method. Copyright $\odot 2005$ IFAC
\end{abstract}

Keywords: Observability; Observers; Process control; Simulation, Waste Treatment.

\section{INTRODUCTION}

Wastewater treatment control is an active research area generally described by complex non-linear systems that include biological, physiochemical and biochemical processes. The main goal of wastewater treatment plants (WWTP) is to achieve sufficiently low concentration of biodegradable matter in the effluent together with minimal sludge production, at a minimum cost. The model considered state of the art for modeling biological nitrogen removal processes is the Activated Sludge Model No. 1 (ASM1) of the International Water Association (IWA) (Henze et al., 2000). This is a complex non-linear model due to multiple time scale dynamics, large perturbation in flow and load, together with uncertainties concerning the composition of the incoming wastewater (Alex et al., 1999). Furthermore, comparing with the ASM2 model, the ASM1 does not include biological phosphorus removal.

In recent years, many activated sludge plants, originally designed for removal of carboneous compounds, have to be upgraded to include nitrogen and phosphorous removal. Consequently, as an integral part of the technological solution, high level of process and automation is required (Hvala et al., 2000). Control of wastewater treatment processes is characterized by the fact that many variables that symbolize the quality of the wastewater are not measured on line and can only be determined by laboratory analysis. Furthermore, to monitor system performance and design control strategy, the engineer must know the states of the system. These states, which are determined through sensors (e.g., optical analyser, turbidity analyser, dissolved oxygen meters) by taking measurement or observation on the system, are often difficult to interpret for control purposes due to noise that contaminates the signal. Therefore, non-linear observers design and implementation is essential to develop robust control strategies in order to achieve efficient plant operation.

The ASM1 model as originally developed is unobservable. Hence many researchers have reformulated or reduced the model based on their understanding of the process without systematically checking the observability properties. The objective of this paper is to develop a systematic procedure to derive 
a reduced-order model from the original ASM1 and perform an observability analysis, essential for observers design.

Observability is an important structural property of dynamic systems defined as the possibility to infer the state of the system from examining its input and output behaviour. The conditions of observability can govern the subsistence of a full solution to the control system design problem. Therefore, if the system is not observable, solutions to solve the control system design may not exist. During the last four decades, this property have continued to be examined since it was first discovered and studied by Kalman in 1960 and later by Kalman et al. in 1962 (Franklin, 2002). Sontag (1979), introduced the concept of algebraic observability for $n$-dimensional polynomial systems. This theory implies the existence of a polynomial expression of the state variables in terms of a finite number of derivatives of the output function. Isidori (1985), developed differential geometric methods in the synthesis of feedback laws for non-linear systems and contributed to outstanding design problems such as feedback linearisation, control, disturbance decoupling, and model matching.

Most observer designs are based on linear observability theory, which affects the acceptability of the proposed results. However, observability theory has been proved on non-linear bioprocess models, based on simplified model that describe few non-linear growth reactions. Delattre et al. (2002), performed an observability analysis of a non-linear tubular reactor that involves one non-linear growth reaction and proved that a finite number of dominant modes are observable under certain conditions. Anguelova (2004), compared two different approaches (differential geometric and algebraic) to test the observability of a kinetic model for $S$. cerevisiae and concluded that there is an upper bound derived for the number of Lie derivatives (for the algebraic approach) that have to be considered in the test for rational systems. Furthermore, Dochain and Vanrolleghem (2001), performed a successful local observability analysis on a two-step nitrification process, and on a simple microbial growth process composed of three state variables.

This paper present a novel contribution based on nonlinear observability analysis, applied on a widely accepted non-linear process model, namely the ASM1 (Henze et al., 2000) and the multi-layers double exponential settling model of Takács et al. (1991). The observability analysis involves seven non-linear growth reactions and the study is performed on a multiple-input multiple-output (MIMO) system composed of six state variables. In Section 2, the process model is derived. Section 3 introduces the observability analysis. In Section 4, results are presented and a general conclusion ends the paper.

\section{IWA /COST SIMULATION BENCHMARK}

Only a short description of the benchmark plant and its process models are provided. For further information the reader should refer to Copp (2002).

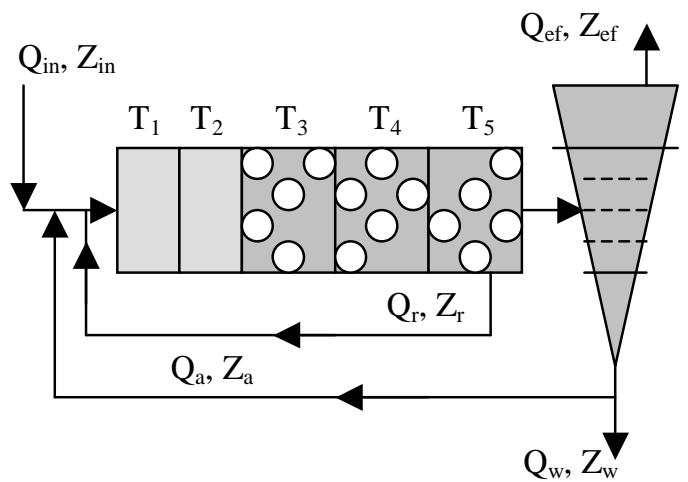

Fig. 1. Plant Layout, where the influent, effluent, internal recycle, external recycle and waste flow rates are $\mathrm{Q}_{\mathrm{in}}, \mathrm{Q}_{\mathrm{ef}}, \mathrm{Q}_{\mathrm{r}}, \mathrm{Q}_{\mathrm{a}}$ and $\mathrm{Q}_{w}$, respectively. The concentrations $Z$ are similarly represented. $\mathrm{T}_{1}$ to $\mathrm{T}_{5}$ represent the anoxic and aerobic reactors.

As seen in Figure (1), the original benchmark plant was considered to be the real plant and the non-linear observability analysis was carried out on the last aerated reactor $\left(\mathrm{T}_{5}\right)$. On-line measurement's locations are not described and are beyond the scope of this paper. The ASM1, which is probably the most widely used representation for describing wastewater treatment processes, was selected to describe biological processes in the activated sludge reactor. The double-exponential settling velocity function proposed by Takács et al. (1991), was chosen to describe the settling process. All simulations were performed on a Matlab/Simulink platform and Maple, based on the open-loop benchmark configuration with the dry and storm weather influent wastewater data.

Assumptions. Soluble inert organic matter $\left(S_{\mathrm{I}}\right)$ contributes to the effluent chemical oxygen demand (COD). Particulate inert organic matter $\left(X_{\mathrm{I}}\right)$ becomes a part of the total suspended solids in the activated sludge system. Therefore, $S_{\mathrm{I}}$ and $X_{\mathrm{I}}$ are removed from the system because they are not contributing to any other reactions and are not involved in any conversion processes. Inclusion of the particulate products arising from biomass decay $\left(X_{\mathrm{P}}\right)$ in the model is an approach of accounting for the fact that not all biomass in the activated sludge system is active (Henze et al., 2000). Insertion of the alkalinity $\left(S_{\mathrm{ALK}}\right)$ in the model is not essential, but its incorporation is advantageous because it provides information by which excessive change in $\mathrm{pH}$ can be predicted (Henze et al., 2000). Therefore, these two components are also removed from the model. Slowly changing variables are assumed constant, which means that the active heterotrophic $\left(X_{\mathrm{B}, \mathrm{H}}\right)$ and autotrophic biomass $\left(X_{\mathrm{B}, \mathrm{A}}\right)$ are kept constant in the reduced model, similar to Ingildsen (2002). Consequently, the particulate biodegradable organic nitrogen $\left(X_{\mathrm{ND}}\right)$, which is generated from decay of both $X_{\mathrm{B}, \mathrm{H}}$ and $X_{\mathrm{B}, \mathrm{A}}$, is also neglected in the reduced model. As a result, the observability analysis is performed on a reduced-order model composed of six state variables, which are: readily and slowly biodegradable substrate $\left(S_{\mathrm{S}}=\mathrm{x}_{1}\right.$ and $\left.X_{\mathrm{S}}=\mathrm{x}_{2}\right)$, dissolved oxygen $\left(S_{\mathrm{O}}=\mathrm{x}_{3}\right)$, nitrate and nitrite nitrogen $\left(\mathrm{S}_{\mathrm{NO}}=\mathrm{x}_{4}\right), \mathrm{NH}_{4}^{+}+\mathrm{NH}_{3}$ nitrogen $\left(S_{\mathrm{NH}}=\mathrm{X}_{5}\right)$, and soluble biodegradable organic nitrogen $\left(S_{\mathrm{ND}}=\mathrm{x}_{6}\right)$ concentrations. 


\section{OBSERVABILITY ANALYSIS}

Throughout this section, the following class of nonlinear systems with outputs (measurements) is considered

$$
\begin{gathered}
\dot{\mathbf{x}}=\mathbf{f}(\mathbf{x}, \mathbf{u}), \quad \text { with } \mathbf{x}(0)=\mathbf{x}_{0} \\
\mathbf{y}_{i}=\mathbf{h}_{i}(\mathbf{x}), \quad 1 \leq i \leq p
\end{gathered}
$$

where $\mathbf{x}$ is the state vector with $n$ states $x_{1}, \ldots x_{n}, \mathbf{u}$ is the input vector with $m$ inputs $u_{1}, \ldots, u_{m}$, and $\mathbf{y}$ the output vector or measurements with $p$ outputs $y_{1}, \ldots, y_{p}$. It is assumed that $\mathbf{x} \in X, \mathbf{u} \in U, \mathbf{y} \in Y$, where $X, U$ and $Y$ are open subsets of $\mathcal{R}^{n}, \mathcal{R}^{m}, \mathcal{R}^{p}$, respectively. The map h: $X \rightarrow Y$ correspond to the vector of $p$ measurements (observation), where $h_{i} \in C^{\infty}(X)$, for $1 \leq i \leq p$ and $\mathbf{h}=$ $\left(h_{1}, \ldots h_{\mathrm{p}}\right)^{T}$. It is also assumed that the system is complete for every bounded measurable input $\mathbf{u}(t)$ and for every $\mathbf{x}_{0} \in X$ there exist a solution to the system (Equation (1)) such that $\mathbf{x}(0)=\mathbf{x}_{0}$ and $\mathbf{x}(t) \in X$ for all $t$ $\in \mathcal{R}$.

The purpose of the following analysis is to determine if the system described by Equations (1) and (2) possesses the local distinguishability property by the so-called "observability rank condition" as established by Herman and Krener (1977). The observability property is related to the distinguishability of initial states position, given only measurements of outputs (and possibly their derivatives) and inputs. Using the general state space model given by Equations (1) and (2), the observation space spanned (or observability map), denoted $\mathbf{w}$, is given by

$$
\mathbf{w}(\mathbf{x})=\left(\begin{array}{c}
w^{1}(\mathbf{x}) \\
w^{2}(\mathbf{x}) \\
\vdots \\
w^{p}(\mathbf{x})
\end{array}\right)
$$

with

$$
\begin{gathered}
\mathbf{w}^{i}(\mathbf{x})=\left(\begin{array}{c}
\mathbf{y}_{i} \\
\dot{\mathbf{y}}_{i} \\
\vdots \\
\mathbf{y}_{i}^{\left(k_{i}-1\right)}
\end{array}\right)=\left(\begin{array}{c}
L_{f}^{0} \mathbf{h}_{i}(\mathbf{x}) \\
L_{f}^{1} \mathbf{h}_{i}(\mathbf{x}) \\
\vdots \\
L_{f}^{k_{i}-1} \mathbf{h}_{i}(\mathbf{x})
\end{array}\right) \\
k=\sum_{i=1}^{p} k_{i}, \quad k \geq n,
\end{gathered}
$$

where $L^{k} h_{\mathrm{i}}$ is the $k$ th Lie derivative along the vector field $\mathbf{f}$ (with $k$ assimilated to the number of state variables), which is define as

$$
\begin{gathered}
L_{f}^{k} h_{i}(\mathbf{x})=\frac{\partial\left(L_{f}^{k-1} h_{i}(\mathbf{x})\right)}{\partial \mathbf{x}} \mathbf{f}(\mathbf{x}, \mathbf{u}), \quad k \geq 1, \\
L_{f}^{0} h_{i}(\mathbf{x})=h_{i}(\mathbf{x})
\end{gathered}
$$

Following this introduction, we are now presenting the non-linear observability definitions as well as the conditions that must be satisfied for that property (Hermann and Krener, 1977).

Definition 1. The non-linear system given by Equations (1) and (2) is globally observable if all initial conditions, $\mathbf{x}_{0}$, can be determined uniquely from $\mathbf{y}(t)$ and $\mathbf{u}(t)$ in the whole domain of definition $\mathbf{x}_{0} \in X, \forall \mathbf{u} \in$ $U$.

This concept can be further supported if the state trajectories progress in a local neighbourhood, leading to local observability property. But on the other hand, the notion of global observability can be seen as weakened by requiring that a given initial state is only distinguishable from its neighbours, leading to the weakly observability property (Francis, 1997). Finally, restricting trajectories to lie in a local neighbourhood can further support the last notion:

Definition 2. The non-linear system given by Equations (1) and (2) is locally weakly observable at $\mathbf{x}_{0}$ if all initial conditions in a neighbourhood, $V$, of $\mathbf{x}_{0}$, which lead to state trajectories remaining in some open neighbourhood $U$ at $\mathbf{x}_{0}$ under control action $\mathbf{u}$, can be uniquely determined from $\mathbf{y}(t)$ and $\mathbf{u}(t)$.

It is important to observe that these definitions are equivalent for linear systems and in addition, it is worth noting that the linear results are independent of the input trajectory. Finally, we give the conditions for evaluating two of the forms of non-linear observability as follow:

Condition 1. The non-linear system given by Equations (1) and (2) is globally observable if $\mathbf{w}^{\mathrm{I}}(\mathbf{x})$ is uniquely invertible with respect to $\mathbf{x}$ in the whole domain of definition.

Condition 2. The non-linear system given by Equations (1) and (2) is locally weakly observable if the Jacobian of $\mathbf{w}(\mathbf{x})$ has full rank in the whole domain of definition.

\section{RESULTS}

The reduced-order ASM1 model under study, described in Section (2), is assumed stable and is described by Equations (1) and (2) where

$$
\begin{gathered}
\mathbf{h}(\mathbf{x})=\left[\begin{array}{llll}
S_{\mathrm{O}} & S_{\mathrm{NO}} & S_{\mathrm{NH}}
\end{array}\right]^{T} \\
\mathbf{f}(\mathbf{x}, \mathbf{u})=\left[\begin{array}{lllll}
f_{1}(\mathbf{x}, \mathbf{u}) & f_{2}(\mathbf{x}, \mathbf{u}) & \cdots & \cdots & f_{6}(\mathbf{x}, \mathbf{u})
\end{array}\right]^{T}(6)
\end{gathered}
$$

with

$$
\begin{aligned}
& f_{1}(\mathbf{x}, \mathbf{u})=\frac{d S_{\mathrm{S}}}{d t}=\mathrm{Q} \frac{S_{\mathrm{S}, \text { in }}-x_{1}}{V_{5}}+\left\{-\frac{\mu_{\mathrm{H}}}{Y_{\mathrm{H}}} \cdot\left(\frac{x_{1}}{K_{\mathrm{S}}+x_{1}}\right) *\right. \\
& {\left[\left(\frac{x_{3}}{K_{\mathrm{O}, \mathrm{H}}+x_{3}}\right)+\eta_{\mathrm{g}} \cdot\left(\frac{K_{\mathrm{O}, \mathrm{H}}}{K_{\mathrm{O}, \mathrm{H}}+x_{3}}\right) \cdot\left(\frac{x_{4}}{K_{\mathrm{NO}}+x_{4}}\right)\right]+} \\
& k_{\mathrm{h}} \cdot \frac{x_{2} / X_{\mathrm{B}, \mathrm{H}}}{K_{\mathrm{X}}+\left(x_{2} / X_{\mathrm{B}, \mathrm{H}}\right)} \cdot\left[\left(\frac{x_{3}}{K_{\mathrm{O}, \mathrm{H}}+x_{3}}\right)+\right.
\end{aligned}
$$




$$
\begin{aligned}
& \left.\left.\eta_{\mathrm{h}}\left(\frac{K_{\mathrm{O}, \mathrm{H}}}{K_{\mathrm{O}, \mathrm{H}}+x_{3}}\right) *\left(\frac{x_{4}}{K_{\mathrm{NO}}+x_{4}}\right)\right]\right\} * X_{\mathrm{B}, \mathrm{H}} \\
& f_{2}(\mathbf{x}, \mathbf{u})=\frac{d X_{\mathrm{S}}}{d t}=\mathrm{Q} \frac{X_{\mathrm{S}, \text { in }}-x_{2}}{V_{5}}+\left\{\left(1-f_{\mathrm{p}}\right)\left(b_{\mathrm{H}} \cdot X_{\mathrm{B}, \mathrm{H}}\right) *\right. \\
& \left(b_{\mathrm{A}} \cdot X_{\mathrm{B}, \mathrm{A}}\right)-k_{\mathrm{h}} * \frac{x_{2} / X_{\mathrm{B}, \mathrm{H}}}{K_{\mathrm{X}}+x_{2} / X_{\mathrm{B}, \mathrm{H}}} *\left[\left(\frac{x_{3}}{K_{\mathrm{O}, \mathrm{H}}+x_{3}}\right)+\right. \\
& \left.\left.\eta_{\mathrm{h}} *\left(\frac{K_{\mathrm{O}, \mathrm{H}}}{K_{\mathrm{O}, \mathrm{H}}+x_{3}}\right) *\left(\frac{x_{4}}{K_{\mathrm{O}, \mathrm{H}}+x_{4}}\right)\right]\right\} * X_{\mathrm{B}, \mathrm{H}} \\
& f_{3}(\mathbf{x}, \mathbf{u})=\frac{d S_{\mathrm{O}}}{d t}=\mathrm{Q} \frac{S_{\mathrm{O}, i n}-x_{3}}{V_{5}}+\left\{-\mu_{\mathrm{H}}\left(\frac{1-Y_{\mathrm{H}}}{Y_{\mathrm{H}}}\right) *\right. \\
& \left(\frac{x_{1}}{K_{\mathrm{S}}+x_{1}}\right) *\left(\frac{x_{3}}{K_{\mathrm{O}, \mathrm{H}}+x_{3}}\right) * X_{\mathrm{B}, \mathrm{H}}-\mu_{\mathrm{A}}\left(\frac{4.57-Y_{\mathrm{A}}}{Y_{\mathrm{A}}}\right) * \\
& \left.\left(\frac{x_{5}}{K_{\mathrm{NH}}+x_{5}}\right)\left(\frac{x_{3}}{K_{\mathrm{O}, \mathrm{A}}+x_{3}}\right) * X_{\mathrm{B}, \mathrm{A}}\right\}+ \\
& K_{L} a \cdot\left(S_{\mathrm{O}, S A T}-x_{3}\right) \\
& f_{4}(\mathbf{x}, \mathbf{u})=\frac{d S_{\mathrm{NO}}}{d t}=\mathrm{Q} \frac{S_{\mathrm{NO}, i n}-x_{4}}{V_{5}}+\left\{-\mu_{\mathrm{H}} \eta_{\mathrm{g}} *\right. \\
& \left(\frac{1-Y_{\mathrm{H}}}{2.86 . Y_{\mathrm{H}}}\right)\left(\frac{x_{1}}{K_{\mathrm{S}}+x_{1}}\right)\left(\frac{K_{\mathrm{O}, \mathrm{H}}}{K_{\mathrm{O}, \mathrm{H}}+x_{3}}\right)\left(\frac{x_{4}}{K_{\mathrm{NO}}+x_{4}}\right) * \\
& \left.X_{\mathrm{B}, \mathrm{H}}-\frac{\mu_{\mathrm{A}}}{Y_{\mathrm{A}}}\left(\frac{x_{5}}{K_{\mathrm{NH}}+x_{5}}\right)\left(\frac{x_{3}}{K_{\mathrm{O}, \mathrm{A}}+x_{3}}\right) * X_{\mathrm{B}, \mathrm{A}}\right\} \\
& f_{5}(\mathbf{x}, \mathbf{u})=\frac{d S_{\mathrm{NH}}}{d t}=\mathrm{Q} \frac{S_{\mathrm{NH}, i n}-x_{5}}{V_{5}}+\left\{-i_{\mathrm{XB}} \mu_{\mathrm{H}} *\right. \\
& \left(\frac{x_{1}}{K_{\mathrm{S}}+x_{1}}\right)\left[\left(\frac{x_{3}}{K_{\mathrm{O}, \mathrm{H}}+x_{3}}\right)+n_{\mathrm{g}} *\left(\frac{K_{\mathrm{O}, \mathrm{H}}}{K_{\mathrm{O}, \mathrm{H}}+x_{3}}\right) *\right. \\
& \left.\left.\left(\frac{x_{4}}{K_{\mathrm{NO}}+x_{4}}\right)\right]+k_{\mathrm{a}} \cdot x_{6}\right\} X_{\mathrm{B}, \mathrm{H}}-\mu_{\mathrm{A}}\left(i_{\mathrm{XB}}+\frac{1}{Y_{\mathrm{A}}}\right) * \\
& \left(\frac{x_{5}}{K_{\mathrm{NH}}+x_{5}}\right)\left(\frac{x_{3}}{K_{\mathrm{O}, \mathrm{A}}+x_{3}}\right) * X_{\mathrm{B}, \mathrm{A}} \\
& f_{6}(\mathbf{x}, \mathbf{u})=\frac{d S_{\mathrm{ND}}}{d t}=\mathrm{Q} \frac{S_{\mathrm{ND}, i n}-x_{6}}{V_{5}}+\left\{-k_{\mathrm{A}} \cdot x_{6}-k_{\mathrm{h}} *\right. \\
& \frac{X_{\mathrm{ND}} / X_{\mathrm{B}, \mathrm{H}}}{K_{\mathrm{X}}+X_{\mathrm{ND}} / X_{\mathrm{B}, \mathrm{H}}} *\left[\left(\frac{x_{3}}{K_{\mathrm{O}, \mathrm{H}}+x_{3}}\right)+\eta_{\mathrm{h}}\left(\frac{K_{\mathrm{O}, \mathrm{H}}}{K_{\mathrm{O}, \mathrm{H}}+x_{3}}\right)\right. \\
& \left.\left.\left(\frac{x_{4}}{K_{\mathrm{NO}}+x_{4}}\right)\right]\right\} * X_{\mathrm{B}, \mathrm{H}}
\end{aligned}
$$

The stoichiometric parameters are the autotrophic yield $\left(Y_{\mathrm{A}}\right)$, the heterotrophic yield $\left(Y_{\mathrm{H}}\right)$, the fraction of biomass to particulate products, and nitrogen in biomass, $\left(f_{\mathrm{p}}, i_{\mathrm{XB}}\right.$, respectively). The kinetic parameters are the maximum heterotrophic growth rate $\left(\mu_{\mathrm{H}}\right)$, the anoxic growth rate correction factor $\left(\eta_{\mathrm{g}}\right)$, the heterotrophic decay rate $\left(b_{\mathrm{H}}\right)$, the anoxic hydrolysis rate correction factor $\left(\eta_{\mathrm{h}}\right)$, the maximum specific hydrolysis rate $\left(K_{\mathrm{h}}\right)$, the maximum autotrophic growth rate $\left(\mu_{\mathrm{A}}\right)$, the autotrophic decay rate $\left(b_{\mathrm{A}}\right)$, the ammonification rate $\left(k_{\mathrm{a}}\right)$, and the half-saturation coefficient for: the heterotrophic growth, the heterotrophic oxygen, the nitrate, hydrolysis, autotrophic growth, and autotrophic oxygen $\left(\mathrm{K}_{\mathrm{S}}, \mathrm{K}_{\mathrm{O}, \mathrm{H}}, \mathrm{K}_{\mathrm{NO}}, \mathrm{K}_{\mathrm{X}}, \mathrm{K}_{\mathrm{NH}}, \mathrm{K}_{\mathrm{O}, \mathrm{A}}\right.$, respectively).

The volume of the fifth tank $\left(V_{5}\right)$ is $1333 \mathrm{~m}^{3}, \mathrm{~K}_{\mathrm{L}} \mathrm{a}$ is the oxygen transfer function, and $S_{\mathrm{O}, S A T}$ the oxygen saturation concentration (set to $8.65 \mathrm{mg} / \mathrm{l}$ in the following simulations). The flow $\mathrm{Q}$ (with the influent flow $\left(Q_{\text {in }}\right)$ equal to the effluent flow $\left(Q_{e f}\right)$ ) and $K_{L}$ a are considered as inputs, and the influent concentrations $\left(S_{\mathrm{S}, \text { in }}, X_{\mathrm{S} \text {,in }}, \ldots, S_{\mathrm{ND} \text {,in }}\right)$ are assumed to be known (from the $4^{\text {th }}$ reactor or second aerobic tank). Even though some of these concentrations cannot be physical inputs (e.g., $S_{\mathrm{S}}, X_{\mathrm{S}}$ ), it is assumed that an observer basedExtend Kalman Filter (EKF) can provide estimates of these non-measurable inputs. For more information about estimation of non-measurable concentrations, the reader should refer to Benazzi et al. (2005). The selected measurements are $S_{\mathrm{O}}, \mathrm{S}_{\mathrm{NO}}$, and $\mathrm{S}_{\mathrm{NH}}$. For few cases, $X_{\mathrm{S}}$ is also assumed available from respirometer or an EKF.

\subsection{Non-linear observability analysis applied on the reduced-order ASM1 model.}

Following the non-linear observability theory derived in Section (3), the observation space spanned $\mathbf{w}(\mathbf{x})$ given by Equation (3) has been computed up to $k=6$ (number of state variables) using the Lie derivative along the vector field $\mathbf{f}$ described by Equation (4). As defined previously (Condition (1)), the system is said globally observable if the inverse $\mathbf{w}^{\mathrm{I}}(\mathbf{x})$ of the observation space spanned exist everywhere (in the state and input space). However, as the solution of Equation (3) is not a trivial problem, global observability can be difficult to consider in practice (Bogaerts and Vande Wouwer, 2004). Therefore, a local weak observability analysis is performed, which leads to study the local invertibility of the of the observability map, in the neighbourhood of a point $\mathbf{x}$. Hence, the system is said locally weakly observable when

$$
\operatorname{rank} \mathcal{Q}(\mathbf{x})=n \text { with } \mathcal{Q}(\mathbf{x})=\frac{\partial \mathbf{w}(\mathbf{x})}{\partial \mathbf{x}}
$$

Results are presented in Figure (2) when dry-weather data are used to characterize the influent wastewater for the reduced-order model.

First, access to one measurement $\left(S_{\mathrm{O}}\right)$ is considered and the local observability test is performed in the neighbourhood of five different operating conditions (points 1 to 5 on the $x$-axis of Figures (2) and (3)). Then, the number of (hypothetically) available measurements is increased to two $\left(S_{\mathrm{O}}\right.$ and $\left.S_{\mathrm{NO}}\right)$, and finally to three $\left(S_{\mathrm{O}}, S_{\mathrm{NO}}\right.$, and $\left.S_{\mathrm{NH}}\right)$ in order to satisfy (when possible) the local weak observability property in the neighbourhood of the selected points (also called operating conditions in this paper), given in Table (1). 


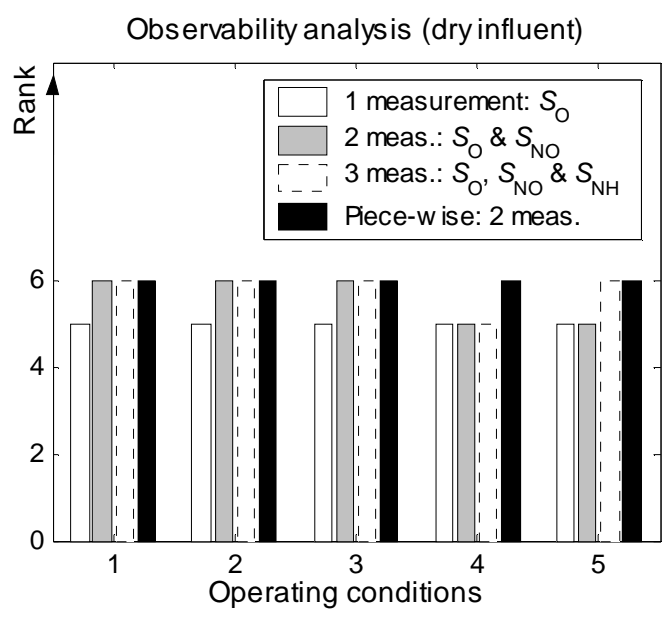

Fig. 2. Non-linear (and piece-wise) observability analysis during dry weather conditions.

The black bars in Figures (2) and (3) are detailed in Section (4.2). Results show that local observability failed at certain points. For instance, when only one measurement is available, the local invertibility of the observability map (rank test) failed at some selected neighbourhood, which indicates that the system is not locally weakly observable in the whole domain of definition. By increasing the number of measurements to two or three, the rank tests (given by Equation (13)) also failed at the fourth operating condition.

Consequently, the number of measurements has been increased to four (assuming $X_{\mathrm{S}}$ from respirometer or an EKF) in order to achieved local observability at the fourth point. However, results are not displayed in Figure (2) as the rank test also failed at the selected operating point. Furthermore, increasing the number of measurements in order to reach local observability is not a suitable solution for the wastewater industry due to the expensive sensors prices.

In Figure (3), the rank test given by Equation (13) is performed when storm influent wastewater data are used to characterize the influent wastewater for the reduced-order model.

Table 1 Operating conditions (OC), which represent the $\mathrm{x}$-axis of Figure (2), used to test the non-linear weak observability of the ASM1 during dry weather conditions (Q: $\mathrm{m}^{3} / \mathrm{d}$ unit; from $S_{\mathrm{S}}$ to $S_{\mathrm{O}}: \mathrm{g} \mathrm{COD} \mathrm{m}^{-3}$ units and from $S_{\text {NO }}$ to $S_{\text {ND }}:=\mathrm{N} \mathrm{m}^{-3}$ units)

\begin{tabular}{cccccc}
\hline $\mathrm{OC}$ & 1 & 2 & 3 & 4 & 5 \\
\hline $\mathrm{Q}_{\text {in }=\text { ef }}$ & 92235 & 90180 & 97825 & 100489 & 93253 \\
$S_{\mathrm{S}, \text { in }}$ & 0.99 & 1.02 & 0.73 & 1.39 & 1.57 \\
$S_{\mathrm{S}}$ & 0.88 & 0.92 & 0.66 & 1.16 & 1.38 \\
$X_{\mathrm{S} \text {,in }}$ & 53.88 & 56.59 & 38.73 & 70.23 & 84.94 \\
$X_{\mathrm{S}}$ & 47.47 & 50.16 & 35.24 & 57.79 & 72.86 \\
$S_{\mathrm{O}, \text { in }}$ & 2.49 & 2.42 & 4.06 & 2.17 & 1.92 \\
$S_{\mathrm{O}}$ & 0.47 & 0.44 & 2.96 & 0.35 & 0.29 \\
$S_{\mathrm{NO}, \text { in }}$ & 9.84 & 9.66 & 11.11 & 6.63 & 5.87 \\
$S_{\mathrm{NO}}$ & 11.08 & 10.74 & 11.78 & 8.23 & 6.48 \\
$S_{\mathrm{NH}, \text { in }}$ & 4.08 & 4.07 & 0.9 & 12.26 & 9.41 \\
$S_{\mathrm{NH}}$ & 2.77 & 2.71 & 0.28 & 10.03 & 8.88 \\
$S_{\mathrm{ND}, \text { in }}$ & 0.76 & 0.77 & 0.61 & 1.05 & 1.06 \\
$S_{\mathrm{ND}}$ & 0.68 & 0.7 & 0.57 & 0.88 & 0.94 \\
\hline & & & & &
\end{tabular}

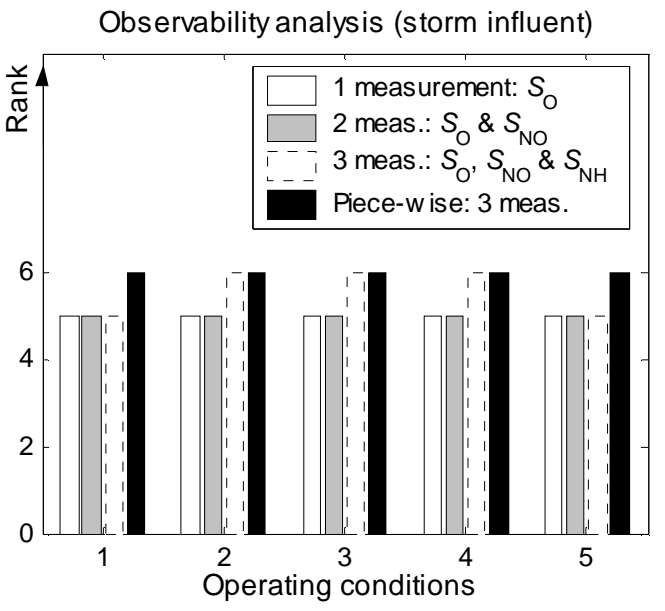

Fig. 3. Non-linear (and piece-wise) observability analysis during storm conditions.

The storm influent is a variation of the dry-weather data (normal diurnal variations) with two different storm events added. It is important to analyse local observability during storm events because the plant reach highly non-linear concentrations at certain points, which cannot be obtained with dry-weather conditions. Consequently, some of these highly non-linear conditions are selected as operating points for the local observability analysis. Results are presented in Figure (3), where it can be seen that local observability failed at certain points. For instance, when using three measurements, the rank test is satisfied for few operating conditions but local observability fails at some selected neighbourhood (first and fifth points). Increasing the number of measurement to three or four, also failed to reach local observability in the whole domain of definition. Therefore, local weak observability is lost at some operating conditions in the whole domain of definition, when three or even four measurements are considered.

\subsection{Piece-wise observability applied on the reduced- order ASM1 model.}

One of the approaches, that is often used in control engineering to check the observability of non-linear models is to use linear observability theory applied piece-wise in time. In other words, it is assumed that exactly the same reduced-order ASM1, as described in Section (2), is composed of a linear model at each sampling point. Under this assumption, the Kalman rank test $\left(\left[\mathbf{C} \mathbf{C A} \ldots \mathbf{C A}^{n-1}\right]\right)$ for observability of linear systems has been successfully applied piece-wise in time (at each sampling point, during 10 days of simulation), assuming up to three measurements. Results are presented in Figures (2) and (3) by the black bars (piece-wise: 2 meas. / 3 meas.) and in each case, these last ones represent more than three thousand operating points. In other words, the Kalman rank test is performed at each sampling time during 10 days of simulation. In the first case (dry influent), two measurements $\left(S_{\mathrm{O}}\right.$ and $\left.S_{\mathrm{NO}}\right)$ are necessary to achieve observability while in the second case (storm influent), three measurements $\left(S_{\mathrm{O}}, S_{\mathrm{NO}}\right.$ and $\left.S_{\mathrm{NH}}\right)$ are required to satisfy the linear observability property in the whole domain of definition. Furthermore, a reduced-order 
ASM1 model composed of eight state variables (six previous state variables, added with $X_{\mathrm{B}, \mathrm{H}}$ and $X_{\mathrm{B}, \mathrm{A}}$ ) has been produced, and the Kalman rank test satisfy the linear observability property in the whole domain of definition, assuming four measurements. However, local observability analysis is not produced in this paper for such model, as local weak observability already failed in the whole domain of definition for the reduced-order ASM1 model composed of six state variables.

\section{CONCLUSIONS}

In this article, a non-linear observability analysis is proposed based on a reduced-order ASM1 model. Local weak observability is achieved under certain operating conditions but fails at some points in the whole domain of definition. These failures occur both during dry and storm conditions regardless of the number of measurements that are considered. A piece-wise linear observability analysis is also performed, and show that observability is achieved with two $\left(S_{\mathrm{O}}\right.$ and $\left.S_{\mathrm{NO}}\right)$, and three $\left(S_{\mathrm{O}}, S_{\mathrm{NO}}\right.$ and $\left.S_{\mathrm{NH}}\right)$ measurements when dry influent, and storm events are considered, respectively.

The difference in the results is defended by the fact that: (1) the piece-wise approach does not include the inputs of the reduced-order model (only the states and outputs are considered for the Kalman rank tests), while for the non-linear method, the inputs, outputs and states are considered for the analysis, and (2) the piece-wise linear technique fails to detect the lack of local observability, probably due to the large step size used by the solver.

These results imply that at some operating conditions, no valid linear models can be derived. Furthermore, the piece-wise linear approach is not valid for non-linear models as it fails to detect the lack of observability at some operating points. However, as the reduced-order ASM1 model is assumed stable and therefore, detectable, observers can be implemented in practice even though local observability will not exist in the whole domain of definition.

\section{ACKNOWLEDGEMENTS}

The authors gratefully acknowledge Camilla Magnussen for insightful comments on the content of the paper and the assistance and support by Dr Ulf Jeppsson, Lund University, Sweden for allowing us to use his Matlab benchmark simulation model implementation. The financial support provided through the European Community's Human Potential Programme under contract HPRN-CT-2001-00200 (WWT\&SYSENG) is gratefully acknowledged.

\section{REFERENCE}

Alex, J., J.F. Beteau, J.B. Copp, C. Hellinga, U. Jeppsson, S. Marsili-Libelli, M.N. Pons, H. Spanjers and H. Vanhooren (2002). Benchmark for Evaluating Control Strategies in Wastewater
Treatment Plants. European Control Conference ECC'99, Germany.

Anguelova, M. (2004). Nonlinear Observability and Identifiability: General Theory and a Case Study of Kinetic Model for S. cerevisiae, (Thesis). School of Mathematical Sciences, Chalmers University of technology and Göteborg University, Göteborg.

Benazzi, F., K.V. Gernaey, U. Jeppsson and R. Katebi. On-line Estimation and Detection of Abnormal Substrate Concentrations in WWTPs using a Software Sensor: A Benchmark Study. Proc. $2^{\text {nd }}$ IWA Conference on Instrumentation, Control and Automation (ICA2005), 29 May - 2 June 2005, Busan, Korea.

Bogaerts, Ph. and A. Vande Wouwer (2004). Parameter identification foe state estimation-application to bioprocess software sensors. Chemical Engineering Science, vol. 59, pp.2465-2474.

Copp, J.B. (Ed.) (2002). The COST Simulation Benchmark. Description and Simulator Manual. ISBN 92-894-1658-0. Office for official publications of the European communities, Luxembourg.

Delattre, C., D. Dochain and J. Winkin (2002). Observability Analysis of a Nonlinear Tubular Bioreactor. Proceedings of the International Symposium on the Mathematical Theory of Networks and Systems (MTNS 2002), University of Notre-Dame, Indiana, USA.

Dochain, D. and P. Vanrolleghem (2001). Dynamical Modelling and Estimation in wastewater Treatment Processes. IWA publishing, London.

Doyle, F.J. (1997). Nonlinear Inferential Control for Process Applications. Journal Process Control. vol. 8, pp. 339-353.

Franklin, G.F., J.D. Powel and A. Emami-Naeini (2002). Feedback Control of Dynamic System. (Prentice Hall edition. ( $4^{\text {th }}$ Edition), pp. 849. Upper Saddle River, New Jersey.

Hvala, N., G. Bavdaz and J. Kocijans (2000). Nonlinear state and Parameter estimation in Batch Biological Wastewater treatment. International journal of systems Science. vol. 32, no. 2, pp. 145-146.

Henze, M., W. Gujer, M. van Loosdrecht and T. Mino (2000). Activated Sludge Model ASM1, ASM2, ASM2d and ASM3. Scientific and Technical Report No 9, IWA publishing, London.

Herman, R. and A.J. Krener (1977). Nonlinear controllability and observability. IEEE Transaction on Automatic Control. vol. 22, no.5, pp. 728-740.

Ingildsen, P. (2002). Realising full-scale control in wastewater treatment systems using in situ nutrient sensors, (Thesis), Department of Industrial Electrical Engineering and Automation, Lund University, Sweden. IBSN 91-88934-00-4.

Isidori, A. (1985). Nonlinear Control Systems. (Fettweis A., Massey J.L., Modestino J.W. and Thoma M. (2nd Edition)), pp 5-14, Springer-Verlag Edition, Germany.

Sontag, E. (1979). On the observability of Polynomial Systems. SIAM Journal Control and Opt. vol 17, pp139-152.

Takács, I., G.G. Patry and D. Nolasco (1991). A Dynamic model of the Clarification Thickening Process. Water Research, vol. 25, no. 10, pp. 12631271. 